\title{
MEDIA DALAM TANTANGAN INDUSTRI 4.0: ANALISIS PENERAPAN SISTEM DIGITALISASI PADA PERUSAHAAN MEDIA TEMPO
}

\author{
Putri Maulina
}

\author{
Program Studi Ilmu Komunikasi, Fakultas Ilmu Sosial dan Ilmu Politik \\ Universitas Teuku Umar \\ Email: putrimaulina@utu.ac.id
}

\begin{abstract}
The development of communication and information technology globally has also influenced the management system of print media companies in Indonesia. The print media platform is currently challenged to be able to improve to be able to maintain its existence amidst technological advancements. Tempo is one of the large print media platforms that until now is still popular with Indonesian audiences and is able to survive. This study aims to examine how Tempo implemented a digitalization system in the process of production and media management. The results of the study describe the Tempo digitalisation process emphasized on several sides: (1) optimizing the media convergence system, by integrating media management systems on print media, internet, e-paper and Tempo TV platforms; and (2) differences in content management on print and online media platforms. The digitalization of the Tempo company as a whole has an impact on the management of media companies, both in terms of human resources and media content produced.
\end{abstract}

Keyword: Print Media, Digitalization, Media Convergence, Tempo

\section{PENDAHULUAN}

Revolusi industri media di dunia sedang berlangsung dengan skala yang cukup besar dan hasil dari revolusi tersebut sudah terlihat. Gelombang digitalisasi telah membawa perubahan dalam dunia media massa dari konvensional menjadi digital Beberapa penerbit surat kabar dan majalah akhirnya tutup dan menghentikan produksi, sementara beberapa penerbit yang lain masih bertahan dengan menyiapkan strategi baru, yaitu melakukan migrasi platform penerbitan ke ruang digital.

Perkembangan industri media massa sangat terkait dengan perkembangan teknologi informasi dan komunikasi. Sebagai konsekuensi dari globalisasi dan modernitas, hubungan ini bersifat saling mempengaruhi. Fungsi teknologi yang mempengaruhi perkembangan industri media massa antara lain meliputi aspek produksi, distribusi, dan pola konsumsi masyarakat. Ini berlangsung terus-menerus sejak penemuan mesin cetak hingga pesatnya penggunaan teknologi internet di berbagai bidang. 
McLuhan (2005) menjabarkan konsep tentang global village, yang menggambarkan bahwa teknologi internet akan membuat masyarakat dunia terkoneksi satu dan lainnya tanpa terdapat batasan apapun. Internet sebagai bentuk perkembangan teknologi, memberikan kemudahan akses informasi bagi masyarakat. Internet juga mencerahkan dunia komunikasi karena dewasa ini teks, audio, dan visual dapat diakses bersamaan dan simultan. Dan hal inilah yang memberikan dampak signifikan terhadap perubahan aktifitas di industri media dunia, khususnya industri media di Indonesia. Saat ini dengan adanya internet sebagai media baru, para pebisnis industri media massa turut memanfaatkan fasilitas internet sebagai sarana publikasi hasil karya jurnalistiknya.

Di Indonesia, perkembangan penggunaan teknologi internet pun sangat signifikan. Seperti apa yang diungkapkan oleh Asosiasi Penyelenggara Jasa Internet Indonesia (APJII) bersama Badan Pusat Statistik (BPS) bahwa jumlah pengguna internet di Indonesia mencapai 71,19 juta orang hingga akhir tahun 2013, dan jumlah tersebut akan terus meningkat pada tahun-tahun berikutnya (Merdeka.com, edisi 15 Januari 2014).

Data tersebut menunjukkan bahwa penggunaan internet sebagai media baru telah dianggap sebagai "berhala" baru di dunia komunikasi. Dengan penegasan lain, lambat laun internet akan mengambil alih hampir semua kemampuan yang dimiliki oleh media konvensional, karena internet mampu memberikan sesuatu yang lebih daripada apa yang bisa diberikan oleh media konvensional kepada khalayak.

Internet menjadi tantangan bagi media-media konvensional untuk tetap mempertahankan eksistensinya. Teknologi komunikasi dan informasi baru (new media) lambat laun mengambil alih hampir semua kemampuan yang dimiliki oleh media konvensional, bahkan pada titik tertentu new media memberikan lebih dari apa yang bisa diberikan oleh media konvensional.

Untuk menyeimbangi kecepatan dan keunggulan dari teknologi internet dalam menyebarkan informasi dan menggapai khalayak media, maka media-media konvensional seperti media cetak, televisi dan radio harus memiliki strategi dan taktik yang baik dalam memanfaatkan perkembangan teknologi dan keberadaan internet tersebut.

Salah satu media yang ikut berpartisipasi di tengah perkembangan teknologi internet ini adalah Tempo Media Group. Sebagai bagian dari industri media cetak yang konvensional, Tempo Media Group juga tertantang untuk memaksimalkan kapasitas sumber daya di institusi media dalam berbagai segi. Karena di tengah-tengah persaingan antar industri media yang semakin gencar, penting bagi Tempo Media Group untuk memanfaatkan keberadaan internet tersebut dalam menunjukkan eksistensi dan memperlebar sayapnya. 
Tempo Media Group tentunya memiliki sikap tersendiri dalam menyikapi perkembangan teknologi dan internet. Bagaimana sikap Tempo di tengah-tengah khalayak modern akan sangat menarik untuk dikaji sebagai bentuk eksistensi media ini di tengah-tengah perkembangan internet serta kemajuan teknologi informasi dan komunikasi.

Kemajuan teknologi informasi dan komunikasi, serta perkembangan internet sebagai salah satu media baru akan sangat berkaitan dengan perkembangan industri media massa di Indonesia. Tempo Media Group adalah salah satu perusahaan media yang tertantang untuk dapat mengikuti arus perkembangan teknologi secara global tersebut. Persaingan bisnis antar media dan ketersediaan teknologi menjadi tantangan bagi Tempo Media Group untuk mempertahankan eksistensinya.

Oleh karena itu, berdasarkan latar belakang permasalahan tersebut dapat dirumuskan beberapa perumusan masalah, yaitu: (1) Bagaimanakah strategi dan taktik konvergensi yang dilakukan oleh Tempo Media Group dalam mempertahankan eksistensi di tengah-tengah khalayak?; (2) Bagaimanakah praktik konvergensi mengubah budaya jurnalisme dan sistem produksi di bagian newsroom Tempo Media Group?

\section{KAJIAN TEORITIS}

\section{Digitalisasi}

Salah satu ciri penting teknologi komunikasi baru menurut yang dijelaskan oleh Feldman, adalah digitalisasi (Hartley, 2002: 165). Digitalisasi membuat manusia dapat menyimpan berbagai informasi di dalam tempat yang kecil. Menurut Nadhya Abrar, digitalisasi memberikan kemudahan pada manusia agar dapat membuat dan mengubah pesan dalam waktu yang singkat. Digitalisasi juga memudahkan manusia untuk menyampaikan informasi melewati batas-batas platform media yang ada (Hayu Rahmitasari, 2017: 190) .

Digitalisasi (bahasa Inggris: digitizing) merupakan sebuah terminologi untuk menjelaskan proses alih media dari bentuk tercetak, audio, maupun video menjadi bentuk digital. Digitalisasi media merupakan proses transformasi media yang semula bersifat analog menjadi digital. Didalam proses digital media, berbagai bentuk fisik dari data input media seperti gambar, suara, teks, dan lain sebagainya, akan dikonversi ke dalam bentuk angka-angka biner sehingga berdampak kepada produksi, distribusi, dan penggunaan atau konsumsi media (Lievrouw, 2011; Liester,et al., 2009; Fieldman, 2005). Media dilepaskan dari realitas fisiknya untuk kemudian berpindah kedalam realitas simbolik komputasional sehingga beragam operasi mampu dilakukan secara bersamaan 
(Liester, et al., 2009). Digitalisasi inilah yang mentransformasikan teknologi media dan komunikasi.

\section{Konvergensi Media}

Konsep konvergensi antara lain dikemukakan Nora dan Mine (1980) dengan term telematique (telematik) untuk menggambarkan kombinasi antara komputer dan teknologi komunikasi. Konvergensi media adalah penggabungan atau pengintegrasian media-media yang ada untuk digunakan dan diarahkan kedalam satu titik tujuan. Konvergensi media biasanya merujuk pada perkembangan teknologi komunikasi digital yang dimungkinkan dengan adanya konvergensi jaringan.

Lynee Cooke menjelaskan bahwa konvergensi media menggabungkan dua atau lebih teknologi media atau sharing informasi melalui teknologi digital (Sambo, 2017: 23). Konvergensi ini sangat mungkin dilakukan jika konten yang diproduksi media telah hadir dalam bentuk digital. Secara struktural konvergensi media berarti integrasi dari tiga aspek, yakni telekomunikasi, data komunikasi, dan komunikasi massa dalam satu medium (Jan van Dijk, 2006: 7). Sedangkan dalam tataran praktis, konvergensi media dapat terjadi pada beberapa level: (1) level struktural seperti kombinasi transmisi data maupun perangkat; (2) level transportasi; (3) level manajemen; (4) level pelayanan; dan (5) level tipe data.

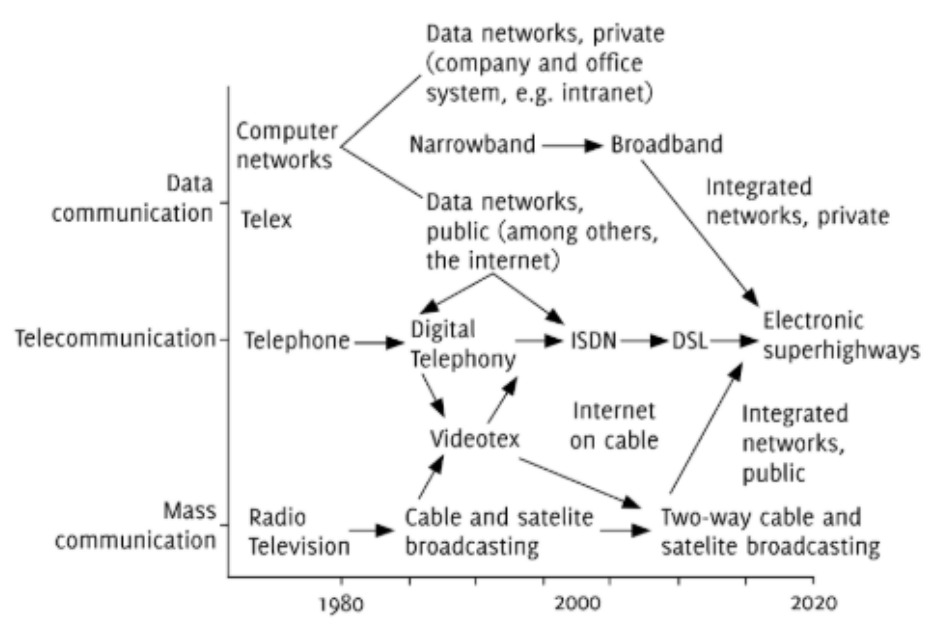

Gambar: Integrasi Transmisi dalam Komunikasi

Sumber: Jan van Dijk. (2006). The Network Society: Social Aspects of New Media. London: Sage, hlm.7. 


\section{METODOLOGI}

Adapun metode kajian yang digunakan adalah kualitatif deskriptif, dengan pendekatan kajian literatur atau kepustakaan. Penulis berupaya membahas secara mendalam tentang strategi Tempo dalam proses konvergensi dan digitalisasi media, dengan mengaitkan sesuai konsep teoritis yang digunakan dan data-data atau dokumen yang telah dikumpulkan sesuai dengan kebutuhan penelitian.

\section{HASIL DAN PEMBAHASAN}

\section{Dampak Internet Terhadap Teknologi, Platforms, dan Inovasi Tempo Media Group}

Perkembangan internet dan didukung dengan keberadaan mobile communication menjadikan orang semakin mudah mengakses informasi media melalui aneka platform. Di Indonesia, proses pengkolaborasian media berangkat dari basis model surat kabar cetak yang berkolaborasi dengan versi online, yang pada tahapan lebih lanjut juga mengikutsertakan medium radio dan televisi menjadi satu platform media.

Proses kolaborasi media cetak dan media internet tersebut merupakan suatu fenomena di mana teknologi komputer dan internet yang bersifat interaktif menyatu dengan teknologi media komunikasi konvensional yang bersifat masif. Fenomena ini lah yang lazim disebut dengan istilah "konvergensi media". Lebih jelasnya, konvergensi media ini adalah berbaurnya media telekomunikasi tradisional dengan internet (KPI, 2013: 165-167).

Terkait dengan permasalahan konvergensi tersebut, tidak ada satupun model konvergensi di dunia yang digunakan oleh Tempo. Mulai akhir 2009, Tempo menjalankan teknik konvergensi media versinya sendiri. Tempo melakukan uji nyali secara terbatas dengan melakukan kompartemen seni yang bekerja melayani semua platform media di bawah kelompok usaha media Tempo. Namun uji coba ini justru tidak memberikan hasil yang memuaskan dikarenakan faktor leadership dari institusi media tersebut, bukan karena faktor model konvergensi yang sedang dikembangkan.

Merespons trend digital yang berkembang di Indonesia, di dalam Laporan Tahunan PT. Tempo Inti Media tahun 2012, dijelaskan bahwa Tempo Media Group sangat memprioritaskan untuk mengembangkan beberapa aplikasi digital. Diantaranya aplikasi digital untuk platform iOS dan Android untuk hampir semua produk cetak Tempo. Tempo Media Group juga sangat serius menanamkan investasi untuk penambahan dan pengembangan infrastruktur server, peningkatan kapasitas bandwidth dan pengembangan situs Tempo.co. 
Maharani (2014) juga menjelaskan bahwa sejak Januari 2012, Tempo telah resmi melakoni konvergensi media. Media Tempo memiliki tiga platform yang dikembangkan secara serentak, yaitu cetak, digital, dan TV. Khusus platform digital, Tempo mengkonvergensikan dalam bentuk Tempo online yaitu menggunakan format aplikasi berbasis tablet untuk majalah, dan menggunakan aplikasi android untuk Koran Tempo. Selain itu Tempo juga memelopori konsep aplikasi berbayar yang bisa diunduh di Scoop dan iTunes.

\section{Gambar: Majalah Tempo Cetak dan Aplikasi Majalah Tempo Berbayar}
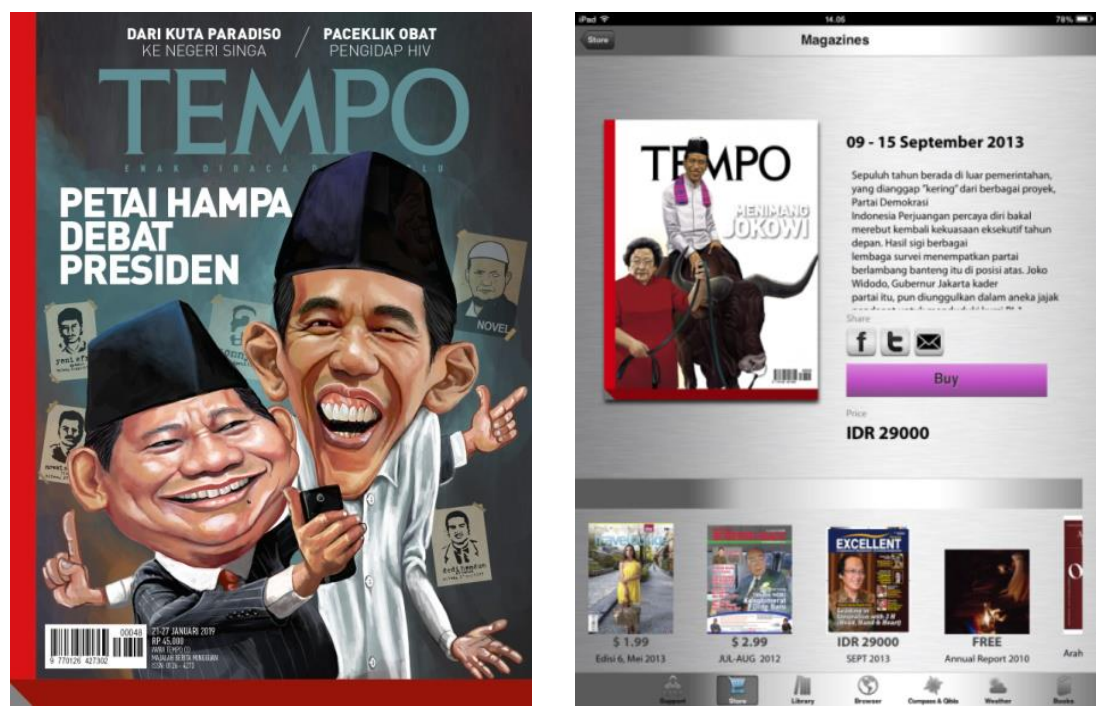

Konvergensi media meliputi lima dimensi besar, yaitu konvergensi teknologi, konten multimedia, kepemilikan, kolaborasi, dan koordinasi (Grant dan Wilkinson, 2009: 3-15). Teknik konvergensi dari Tempo Media Group yang membuat media tersebut tetap bertahan adalah dengan membuat platform baru yaitu "Tempo.co", suatu situs pemberitaan online yang dapat diakses tanpa menggunakan biaya. Selain itu, pembaca juga dapat berlangganan e-magazine Tempo dengan membuat akun berbayar terlebih dahulu.

Tempo.co ini menjadi trendsetter berita online sejak diluncurkan 23 November 2011 menggantikan situs berita Tempo Interaktif. Setiap bulan jumlah pengunjungnya terus meningkat. Rata-rata setiap bulan situs ini dikunjungi oleh 11 juta orang. Begitu pula dengan peningkatan jumlah halaman yang rata-rata dikunjungi sekitar 55 juta per bulan. Peningkatan itu terjadi berkat inovasi isi media yang terus dilakukan, diantaranya dengan menambahkan tampilan audio dan video dan sajian infografik. 
Praktik konvergensi media mensyaratkan satu hal, yaitu penyatuan lokasi newsroom. Jika Tempo Media Group yang memiliki beberapa format media dan menjalankan praktik konvergensinya dari sejumlah lokasi newsroom yang terpisah, akan menjadi suatu permasalahan dan memberikan suatu kendala. Oleh karena itu, Tempo Media Group kemudian menjalankan penyatuan lokasi newsroom di Kebayoran Lama, Jakarta Selatan. Sehingga proses agregasi dan konvergensi media bisa lebih mudah dijalankan. Sistem konvergensi ini menjadikan media lama dan media baru hidup bersama dan saling berinteraksi.

\section{Gambar : Majalah Tempo di Tablet, Tempo.co, dan Koran Tempo di Android}
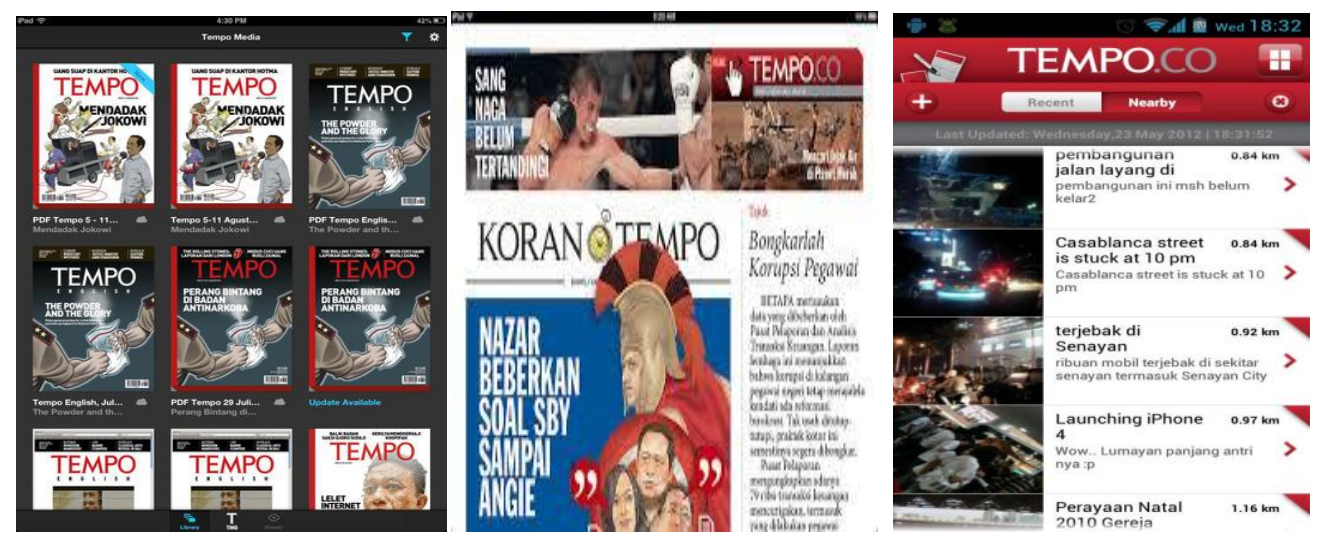

Inovasi adalah penting dalam proses konvergensi media. Dengan berkembangnya teknologi maka pembaca juga akan mengikuti tren teknologi seperti penggunaan gadget dan mulai meninggalkan media cetak. Tempo Media Group memanfaatkan perkembangan teknologi informasi dan komunikasi tersebut dengan memaksimalkan aplikasi Tempo digital yang dapat diakses dengan mudah di Ipad dan Smartphone atau mendownload aplikasi Koran Tempo di Android Playstore. Dengan inovasi yang telah gencar dilakukan oleh Tempo Media Group tersebut, maka khalayak saat ini tidak hanya dapat menikmati informasi terkini khas Tempo melalui kanal-kanal berita pilihan, seperti Bisnis, Metro, Politik, Dunia, Bola, Olahraga, Otomotif, Gaya, Seleb, Travel, tetapi juga suguhan infografik yang menarik serta tampilan audio dan video yang memikat. 


\section{Gambar: Tempo TV}

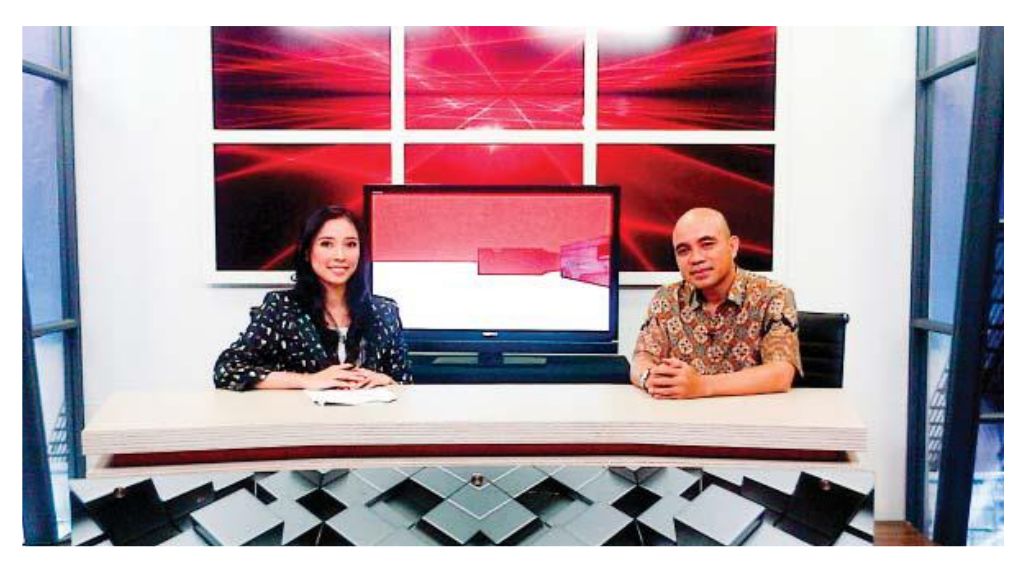

Tempo Media Group juga mengembangkan platform media televisi untuk menyajikan informasi ke ruang publik yang berlandaskan pada kerja jurnalisme yang berkualitas di tengah-tengah media televisi lainnya yang cenderung mengedepankan konsep hiburan dan komersialisasi informasi. Tempo TV didirikan oleh Tempo Media Group pada tahun 2009 dan tayang selama 24 jam di televisi berlangganan Aora TV. Selama ini, Tempo TV Tempo TV telah memproduksi ratusan episode program yang disiarkan televisi lokal.

Perkembangan internet dan teknologi juga menuntut Tempo TV untuk menjajaki dunia digital serta memanfaatkan perangkat teknologi informasi dan komunikasi. Pada 2013, Tempo TV telah merencanakan untuk memaksimalkan inovasinya dengan bekerja sama dengan salah satu perusahaan untuk mengisi i-Pad, Android, dan smart TV (LG). Juga menjajaki televisi digital dengan cara bekerja sama dengan perusahaan yang memiliki ijin sebagai penyedia multiplexing di wilayah Jakarta dan sekitarnya.

\section{Dampak Internet Terhadap Isi Media}

Dalam menjalankan aktivitas jurnalistik, maka setelah Tempo Media Group menerapkan sistem konvergensi dan kolaborasi dalam bentuk media online "Tempo.co", budaya jurnalisme dalam media Tempo pun ikut mengalami perubahan. Reporter media Tempo dituntut untuk dapat berpikir digital dalam satu waktu, karena mereka berpacu dengan deadline. Para jurnalis Tempo juga harus dapat melayani tiga outlet sekaligus, yaitu majalah, koran, dan online. Dalam proses peliputan berita, Tempo menekankan suatu prinsip bahwa satu pemberitaan yang terdapat dalam satu platform berarti tidak boleh terdapat dalam platform lainnya. Ini tentu saja dapat menjadi suatu kendala dalam 
newsroom Tempo, khususnya bagi Tempo.co yang menghendaki banyak pemberitaan dalam waktu cepat namun harus menjaga kualitas.

Preston (2001) memperingatkan bahwa konvergensi akan membawa dampak pada perubahan radikal dalam hal penanganan, penyediaan, distribusi, dan pemrosesan seluruh bentuk informasi secara visual, audio teks, data, dan sebagainya. Konvergensi akan berdampak pada segala bidang kehidupan, contohnya seperti strategi jurnalistik konvensional akan berubah amat radikal. Para jurnalis di media tempo tertuntut untuk bergerak lebih cepat dari biasanya dan sesegara mungkin mengirimkan informasi yang diperolehnya ke masyarakat (KPI, 2013: 169).

Dampak yang terlihat jelas adalah pada jenis pemberitaan Tempo di media online. Tempo.co berhasil menyajikan pemberitaan dengan cepat, namun kualitas pemberitaan tidak sebaik pemberitaan di media Tempo edisi cetak seperti yang terbit di majalah dan koran. Hal ini terjadi karena reporter Tempo yang terus-menerus dikejar oleh deadline pemberitaan untuk menyesuaikan kecepatan dari karakteristik media online dan kebutuhan pembaca di media tersebut. Pemberitaan Tempo.co yang kerap menimbulkan komentar pro dan kontra oleh khalayak media terhadap sosok yang diberitakannya dan dianggap tidak berkualitas daripada pemberitaan di Tempo Cetak.

Seperti yang dijelaskan oleh Kung, Picard, dan Towse (2008: 78), bahwa kesuksesan pengembangan bisnis konvergensi media tetaplah bersandar pada faktor konten yang mana kualitas dan kredibilitas konten menjadi basis utama bisnis media. Masih banyaknya potensi pelanggaran etika jurnalistik yang berasal dari platform media online, seperti Tempo.co yang lebih mengedepankan kecepatan dibanding akurasi sehingga konten media tersebut harus lebih mendapatkan perhatian. Pembaca saat ini sudah cenderung lebih cerdas dalam memilih dan menilai pemberitaan yang layak untuk dibaca, sehingga jika Tempo mengabaikan kualitas konten demi ketersediaan berita maka akan membuat akuntabilitas media tersebut buruk di mata khalayak.

Terkait dengan masalah format tampilan online surat kabar, meskipun format isi Koran Tempo versi online juga dituntut untuk tampil sama dengan versi cetaknya. Namun demikian, teknisi Koran Tempo online akan mengorganisir isi koran online secara berbeda daripada koran versi cetak dengan mempertimbangkan kebutuhan khalayak. Jika halaman depan Koran Tempo cetak mengedepankan menampilkan berita yang mencakup elemen-elemen isi pemberitaan secara keseluruhan, maka halaman depan Koran Tempo online justru menampilkan ikhtisar isi pemberitaan keseluruhan untuk ditemukan pada halaman lainnya. Hal tersebut membuat Koran Tempo versi cetak lebih kaya isi dan memiliki struktur yang sederhana daripada koran online. Halaman depan dari Koran 
Tempo online menggambarkan titik awal untuk arah pembaca, di mana pembaca memiliki banyak pilihan untuk menentukan apa yang penting dibaca atau tidak. Sedangkan halaman depan Koran Tempo cetak, justru menggambarkan berita apa yang dianggap penting oleh editor sehingga harus dibaca oleh khalayaknya.

\section{Gambar: Tampilan Koran Tempo Cetak \& Online}

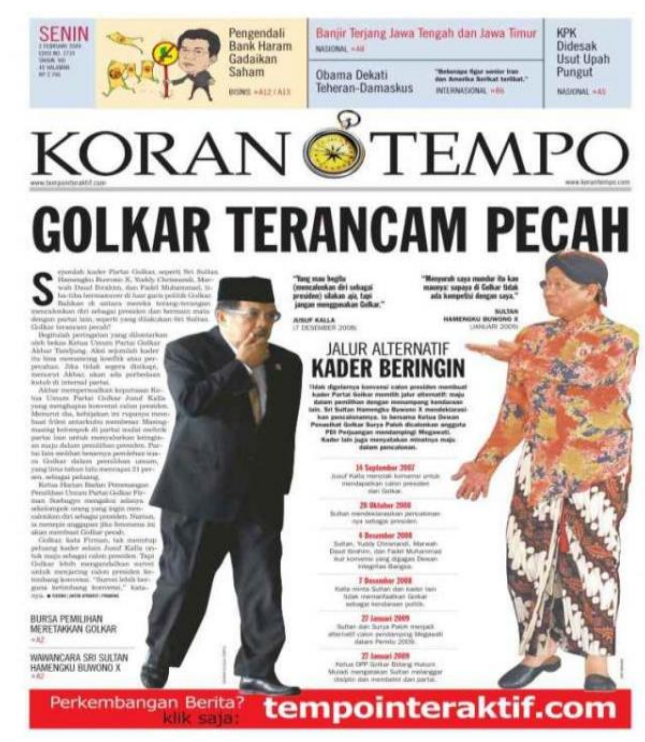

Lebih lanjut dampak dari konvergensi tersebut ternyata amatlah besar untuk mengubah ciri-ciri komunikasi massa konvensional, seperti media cetak. Dalam hal umpan balik misalnya, yang biasanya pada media cetak selalu tertunda akan berkurang bahkan mungkin bisa saja akan lenyap sama sekali. Dan jika dikaitkan dengan kepentingan-kepentingan kelompok tertentu, maka keberadaan media yang konvergen akan dimanfaatkan untuk menyebarkan gagasan-gagasan politik secara lebih leluasa dibandingkan dengan media cetak yang konvesional, sehingga perhatian pun akan menjadi lebih besar ditujukan pada media yang konvergen tersebut. Media Tempo juga akan dengan mudahnya menyebarkan kepentingannya melalui pemanfaatan teknologi dan internet tersebut, baik kepentingan bisnis media atau kepentingan lainnya yang menguntungkan tokoh politik tertentu. 


\section{PENUTUP}

Dari pembahasan yang telah dijabarkan, maka dapat diambil beberapa kesimpulan:

a. Strategi dan taktik konvergensi yang dilakukan oleh Tempo Media Group dalam mempertahankan eksistensi di tengah-tengah khalayak adalah dengan melakukan bentuk konvergensi media. Konvergensi yang dilakukan oleh Tempo Media Group adalah dengan membuat penyatuan newsroom, yang menggabungkan beberapa media seperti Majalah Tempo, Tempo.co, Koran Tempo, dan Tempo TV/Radio ke dalam satu platform.

b. Model konvergensi yang dilakukan oleh Tempo Media Group menjadikan media tersebut tetap eksis di tengah-tengah persaingan dengan media-media lainnya, yang memberikan kemudahan akses informasi bagi khalayak Indonesia.

c. Model jurnalisme berbasis konvensional tidak akan mampu membuat Tempo Media Group tetap eksis. Sikap Tempo Media Group yang benar-benar memanfaatkan perkembangan teknologi informasi dan komunikasi tersebut, serta memaksimalkan keberadaan internet menunjukkan adanya perubahan budaya jurnalisme dalam institusi media tersebut ke arah yang lebih modern. Jurnalisme modern dengan model konvergensi menjadikan Tempo lebih dekat dengan khalayak dan mampu mengikuti perkembangan global.

\section{REFERENSI}

Grant, August E. \& Meadows, Jennifer H. (2008). Communication Technology Update and Fundamental. USA: Focal Press.

Hayu Rahmitasari,Diyah. 2017. Manajemen Media di Indonesia. Jakarta: Yayasan Pustaka Obor.

Komisi Penyiaran Indonesia. (2013). Kedaulatan Frekuensi: Regulasi Penyiaran, Peran KPI, dan Konvergensi Media. Jakarta: PT. Kompas Media Nusantara.

Kung, Picard, dan Towse. (2008). The Internet and the Mass Media. London: Sage Publications.

Maharani, Ayu Nanda. (2014). Tempo Siasati Isu Konvergensi Media. (http://mediaclubonline.blogspot.com/2014/10/tempo-siasati-isu-konvergensi-media.html, diakses 18 Desember 2014).

Nasrullah, Rulli. (2014). Teori dan Riset Media Siber (Cybermedia). Jakarta: Kencana. 
Preston, Paschal. (2001). Reshaping Communications: Technology, Information and Social Change. SAGE London. Setiawan, Judhie. (2009). Konvergensi Teknologi dan Media (internet). Tersedia dalam :

http://www.slideshare.net/judhie/konvergensi (diakses 20 Desember 2014).

Laporan Tahunan. (2012). PT. Tempo Inti Media TBK.

Sambo, Masriadi dan Yusuf, Jafaruddin. (2017). Pengantar Jurnalisme Multiplatform. Jakarta: Kencana. 